\title{
Orosomucoid expression profiles in liver, adipose tissues and serum of lean and obese domestic pigs, Göttingen minipigs and Ossabaw minipigs
}

Højbøge, Tina Rødgaard; Stagsted, Jan; Christoffersen, Berit $\varnothing$.; Cirera Salicio, Susanna;

Moesgaard, Sophia Gry; Sturek, Michael; Alloosh, Mouhamad ; Heegaard, Peter M. H.

Published in:

Veterinary Immunology and Immunopathology

DOI:

10.1016/j.vetimm.2012.11.002

Publication date:

2013

Document version

Early version, also known as pre-print

Citation for published version (APA):

Højbøge, T. R., Stagsted, J., Christoffersen, B. Ø., Cirera Salicio, S., Moesgaard, S. G., Sturek, M., Alloosh, M., \& Heegaard, P. M. H. (2013). Orosomucoid expression profiles in liver, adipose tissues and serum of lean and obese domestic pigs, Göttingen minipigs and Ossabaw minipigs. Veterinary Immunology and Immunopathology, 151(3-4), 325-330. https://doi.org/10.1016/j.vetimm.2012.11.002 


\title{
Orosomucoid expression profiles in liver, adipose tissues and serum of lean and obese domestic pigs, Göttingen minipigs and Ossabaw minipigs
}

\author{
Tina Rødgaard ${ }^{\mathrm{a}}$, Jan Stagsted ${ }^{\mathrm{b}}$, Berit $\emptyset$. Christoffersen $^{\mathrm{c}}$, Susanna Cirera ${ }^{\mathrm{d}}$, \\ Sophia G. Moesgaard ${ }^{\mathrm{d}, 1}$, Michael Sturek ${ }^{\mathrm{e}}$, Mouhamad Alloosh ${ }^{\mathrm{e}}$, Peter M.H. Heegaard ${ }^{\mathrm{a}, *}$ \\ a Innate Immunology Group, National Veterinary Institute, Technical University of Denmark, Frederiksberg C, Denmark \\ b Department of Food Science, Aarhus University, Tjele, Denmark \\ c Novo Nordisk A/S, Maaløv, Denmark \\ ${ }^{\mathrm{d}}$ Department of Veterinary Clinical and Animal Sciences, Faculty of Health and Medical Sciences, University of Copenhagen, Frederiksberg C, Denmark \\ e Department of Cellular and Integrative Physiology, Indiana University School of Medicine, Indianapolis, IN, USA
}

\section{A R T I C L E I N F O}

\section{Article history:}

Received 13 September 2012

Received in revised form 30 October 2012

Accepted 2 November 2012

\section{Keywords:}

Swine

PCR

Innate immunity and gene transcripts

\begin{abstract}
A B S T R A C T
The acute phase protein orosomucoid (ORM) has anti-inflammatory and immunomodulatory effects, and may play an important role in the maintenance of metabolic homeostasis in obesity-induced low-grade inflammation. Even though the pig is a widely used model for obesity related metabolic symptoms, the expression of ORM has not yet been characterized in such pig models. The objective of this study was to investigate the expression of ORM1 mRNA in liver, visceral adipose tissue, subcutaneous adipose tissue (SAT) from the abdomen or retroperitoneal abdominal adipose tissue (RPAT) and SAT from the neck, as well as the serum concentration of ORM protein in three porcine obesity models; the domestic pig, Göttingen minipigs and Ossabaw minipigs.

No changes in ORM1 mRNA expression were observed in obese pigs compared to lean pigs in the four types of tissues. However, obese Ossabaw minipigs, but none of the other breeds, showed significantly elevated ORM serum concentrations compared to their lean counterparts. Studies in humans have shown that the expression of ORM was unchanged in adipose tissue depots in obese humans with an increased serum concentration of ORM. Thus in this respect, obese Ossabaw minipigs behave more similarly to obese humans than the other two pig breeds investigated.
\end{abstract}

(C) 2012 Elsevier B.V. All rights reserved.

\section{Introduction}

Obesity is accompanied by low-grade systemic inflammation, which may contribute to development of obesity-associated metabolic abnormalities, such as

\footnotetext{
* Corresponding author at: Innate Immunology Group, DTU Veterinary, Bülowsvej 27, Building B, 1870 Frederiksberg C, Denmark.

Tel.: +45 35886241; fax: +4535886001.

E-mail address: pmhh@vet.dtu.dk (P.M.H. Heegaard).

1 Present address: Novo Nordisk A/S, Maaløv, Denmark.
}

atherosclerosis, type 2 diabetes and cardiovascular diseases (Bastard et al., 2006; Federico et al., 2010; Gil et al., 2007). A number of immune factors are involved in this low-grade inflammation and several of these factors are produced in the adipose tissues as well as other tissues (reviewed in for example Fain, 2010; Fantuzzi, 2005). A well-regulated acute inflammatory response is a selflimiting and localized non-adaptive response to tissue destruction/perturbation, whether it is of infectious or of aseptic origin. In contrast, the inflammatory response seen in obesity is systemic and chronic with few acute clinical manifestations, being rather characterized by a slightly 
perturbed inflammation marker serum profile and having no easily definable targets (Fain, 2010). Prolonged and exaggerated inflammation is known to be detrimental to the host tissue and several studies have shown that even small changes in the levels of inflammation markers such as acute phase proteins (APPs) are associated with serious long-term complications (Ebeling et al., 1999; Ridker et al., 1998, 2000).

Orosomucoid (ORM), also known as alpha-1 acidglycoprotein, is a member of the APP family and is synthesized mainly hepatically, however, extrahepatic synthesis has been reported including in adipose tissue (Fournier et al., 2000). ORM has anti-inflammatory and immunomodulatory properties, including anti-neutrophil and anti-complement activity functions (Hochepied et al., 2003; Williams et al., 1997). Humans have two isoforms ORM1 and ORM2 and pigs have one isoform (Fournier et al., 2000; Stone and Maurer, 1987). ORM is induced in response to metabolic and inflammatory signals in the adipose tissue of several types of obese mice accompanied by an increase in plasma concentration (Lee et al., 2010). Serum ORM concentrations in obese humans are significantly higher than those seen in lean individuals (Alfadda et al., 2012; Lee et al., 2010), however, no relationship between ORM1 expression in adipose tissues and ORM serum levels of obese humans could be demonstrated. In addition no differential expression in adipose tissues in obese humans was found (Alfadda et al., 2012). We have been unable to identify any published data examining the mRNA expression of ORM in liver and adipose tissues between lean and obese humans. The presence of ORM1 in adipose tissues may help maintain metabolic homeostasis by suppressing local and systemic inflammation (Lee et al., 2010). Interestingly, evidence suggests that porcine ORM is a negative APP (Skovgaard et al., 2009), as opposed to all other investigated mammals. The expression of ORM in obese pigs has not been thoroughly investigated, even though the pig is growing in popularity as a model animal for obesity (Litten-Brown et al., 2010), however, a proteomic analysis of blood serum in lean and obese Ossabaw pigs on an atherogenic diet demonstrated increased serum concentrations of ORM in the obese pigs (Bell et al., 2010).

In this study we investigated ORM gene expression in liver and adipose tissues, as well as ORM serum protein concentrations in three types of lean and obese pigs; the domestic pig, the Ossabaw and the Göttingen minipig. As both the Ossabaw and Göttingen minipigs have been proposed to be very good model animals for human obesity (Bellinger et al., 2006; Litten-Brown et al., 2010), they are expected to have a similar ORM response as humans, i.e. no differential ORM1 expression in adipose tissues of obese pigs and raised ORM serum levels in obese pigs compared to lean (Alfadda et al., 2012; Lee et al., 2010).

\section{Materials and methods}

\subsection{Animals, diets and sampling}

\subsubsection{Domestic pig (Danish landrace/Yorkshire)}

All experimental procedures involving domestic pigs (intercross containing 75\% Danish Landrace:25\% Yorkshire) were approved by the Danish Animal Experiments Inspectorate. They were all female and reared and housed in the same experimental stables of Aarhus University (Tjele, Denmark). At three months of age the pigs were fed a high-energy diet (containing $10 \%$ sugar and $10 \%$ soy oil, as described by Christensen et al. (2012)) ad libitum (obese, $n=10$ ) or at $60 \%$ intake (lean, $n=9$ ). At 8-9 months the pigs were euthanized and tissue samples from liver, abdominal s.c. adipose tissue (SAT) (a combination of deep and superficial SAT), mesenteric fat surrounding the appendix (VAT) and s.c. fat from the neck (neck SAT) were obtained and snap frozen in liquid nitrogen, and blood was collected for serum preparation. Tissue and serum samples were kept at $-80^{\circ} \mathrm{C}$ until analysis.

\subsubsection{Göttingen minipigs}

All experimental procedures involving Göttingen minipigs were approved by the Danish Animal Experiments Inspectorate. Female, ovariectomized Göttingen minipigs (Ellegaard Göttingen Minipigs A/S (Dalmose, Denmark)) were housed at the University of Copenhagen (Taastrup, Denmark). The obese pigs had previously been used in pharmacological studies with therapeutic peptides, but had been subjected to a suitable wash-out period prior to this study. Lean pigs $(n=7)$ were fed minipig standard chow; Altromin $90232 \times 150 \mathrm{~g}$ a day and obese pigs $(n=7)$ were fed minipig standard chow; Altromin 9033 ad libitum. The minipigs were euthanized at 41-47 months of age with pentobarbital and tissues were collected from the liver, neck SAT, cranioventral retroperitoneal abdominal adipose tissue (RPAT) and VAT and snap frozen in liquid nitrogen, and blood was collected for serum preparation. Tissue and serum samples were kept at $-80^{\circ} \mathrm{C}$ until analysis.

\subsubsection{Ossabaw minipigs}

All experimental procedures involving Ossabaw minipigs were approved by the Indiana University Animal Care and Use Committee and complied fully with the Guide for the Care and Use of Laboratory Animals and the American Veterinary Medical Association Panel on Euthanasia. Female Ossabaw miniature swine were obtained from the Indiana University School of Medicine and Purdue University breeding colony (West Lafayette, IN, USA). At the age of 6 months, pigs were divided into two groups and fed either a lean standard chow diet of $2200 \mathrm{kcal}$ per day with $10.5 \%$ of the total energy derived from fat (lean, $n=7$ ) or an excess calorie fructose and fat atherogenic diet of 4500-6000 kcal per day with $43 \%$ of the total energy derived from fat (obese, $n=5$ ) for 30-40 weeks (Lee et al., 2009). At the end of the feeding programs animals were euthanized by cardiectomy under anaesthesia induced by tiletamine-zolazepam $(5 \mathrm{mg} / \mathrm{kg})$ and xylazine $(2.2 \mathrm{mg} / \mathrm{kg})$ given intramuscularly. After euthanasia, samples of liver, abdominal SAT and VAT were collected and snap frozen. No neck SAT samples were collected from Ossabaw minipigs. Liver samples were retrieved from all animals while adipose tissue samples were obtained from 4 of the lean pigs and 3 of the obese pigs. Blood was collected for serum preparation. Serum and tissue samples were stored at $-80^{\circ} \mathrm{C}$ until analysis. 


\subsection{RNA extraction}

For all types of pigs liver RNA was extracted using RNeasy Lipid tissue Midi kit (Qiagen, Copenhagen, Denmark) according to the manufacturer's protocol and any DNA present was removed from the samples using on-column RNase-free DNase digestion (Qiagen).

Extraction of RNA from the adipose tissues of the lean domestic pigs was done as described in (Rødgaard et al., 2012), using approximately $1 \mathrm{~g}$ of tissue.

For four of the obese domestic pigs, abdominal SAT RNA was isolated by the column-based RNeasy Lipid tissue Midi kit (Qiagen) according to manufacturer's protocol and treated with on-column RNase-free DNase digestion (Qiagen). For the remaining 6 obese domestic pigs, and the VAT and neck SAT of all the obese domestic pigs, a similar method was used but without the columns. Briefly, approximately $1 \mathrm{~g}$ of adipose tissue was homogenized with QIAzol Lysis Reagent (Qiagen), and chloroform was added. After centrifugation, isopropanol was added to the upper, aqueous phase. After another centrifugation step the pellet was washed three times in ethanol and RNA was dissolved in RNase-free water.

For extraction of RNA from the adipose tissues of the Göttingen and Ossabaw minipigs, approximately $1 / 2 \mathrm{~g}$ of adipose tissue was homogenized with QIAzol Lysis Reagent and centrifuged. Chloroform was added followed by isopropanol after centrifugation. The pellet was washed 2 times in ethanol and RNA was dissolved in RNase-free water.

RNA yields were measured on a NanoDrop (Spectrophotometer ND-1000, NanoDrop Technologies Inc, USA) and the RNA integrity number (RIN) was determined by electrophoresis in the Agilent 2100 Bioanalyzer (Agilent Technologies, CA, USA), with the use of Agilent RNA 6000 Nano Kit (Agilent Technologies) according to the manufacturer's protocol. $500 \mathrm{ng}$ of total RNA was reverse transcribed using the QuantiTECT Reverse Transcription kit (Qiagen), according to the manufacturer's instructions.

\subsection{Quantitative real time PCR ( $q P C R$ )}

qPCR was performed on a Rotor-Gene Q instrument (Qiagen) using SYBR Green Jumpstart Taq Readymix without $\mathrm{MgCl}_{2}$ (Sigma, Brøndby, Denmark). Each sample was run in triplicates for the ORM1 gene and for two reference genes (GAPDH and RPL13A) that were pre-selected based on previous experiences with the samples (data not shown) using GeNorm (Vandesompele et al., 2002). Non template controls (NTC) and samples without reverse transcriptase in the cDNA synthesis were included as negative controls. Primers were designed as described previously (Skovgaard et al., 2009). Primers are described in Table 1.

The following cycling parameters were used: $5 \mathrm{~min}$ at $95^{\circ} \mathrm{C}$ followed by 40 two-step cycles of $5 \mathrm{~s}$ at $95^{\circ} \mathrm{C}$ and $10 \mathrm{~s}$ at $60^{\circ} \mathrm{C}$ (for ORM1) or $62^{\circ} \mathrm{C}$ (for GAPDH and RPL13A). Melting curves were generated after each run (from $50^{\circ} \mathrm{C}$ to $99^{\circ} \mathrm{C}$, increasing $1{ }^{\circ} \mathrm{C} / 5 \mathrm{~s}$ ) to confirm amplification of a single PCR product. Expression data were acquired using the Rotor-Gene Q series software, v. 2.0.2 (Qiagen) and exported to GenEx5 (MultiD, Göteborg, Sweden).

\subsection{Serum protein quantification with enzyme-linked immunosorbent assay (ELISA)}

ORM was analyzed by a competitive catching ELISA in which a mouse monoclonal antibody specific for porcine ORM was used as the catching antibody in the coating layer (1.62, prepared in-house, Heegaard et al., in preparation). This was followed by simultaneous incubation with sample and biotinylated ORM purified from a porcine serum pool. Pooled pig serum calibrated against a porcine ORM calibrator (Saikin Kagaku Institute Co. Ltd., Japan) was used as a standard. The detection limit of the assay was $50 \mu \mathrm{g} / \mathrm{mL}$. Outliers were identified by Grubbs outlier test (Grubbs, 1969), and removed from the dataset.

\subsection{Data analysis and statistics}

qPCR data pre-processing was done using GenEx5. Data were corrected for differences in PCR efficiencies for each primer assay individually and the geometric mean of the reference genes was used to normalize all samples. Relative expression for all samples was calculated relative to the least expressed samples for each primer assay. Gene expression data were $\log 2$ transformed in order to fit a normal distribution prior to one-way ANOVA with Tukey-Kramer posttest. Statistics were performed in GraphPad Prism v.5.02 (GraphPad Software, California, USA). For ELISAs significance was tested using a two-tailed unpaired $t$-test. Changes were considered to be significant if $p \leq 0.05$. Data are expressed as the mean \pm standard error of the mean (SEM).

\section{Results and discussion}

ORM has been implemented in maintaining metabolic homeostasis and suppressing obesity-induced low-grade inflammatory responses (Lee et al., 2010), therefore we studied the expression of ORM in lean and diet-induced obese pigs from three obesity relevant breeds. For all breeds, the mean body weight at the time of slaughter was significantly higher for the obese animals than for the lean animals (domestic pigs - $119.1 \pm 3.2$ (lean) vs. $170 \pm 4.9 \mathrm{~kg}$ (obese), $p=0.03$; Göttingen minipigs - $50.3 \pm 1.6$ (lean) vs. $92.6 \pm 5.2 \mathrm{~kg}$ (obese), $p<0.0001$; Ossabaw minipigs $60.4 \pm 7.6$ (lean) vs. $100.0 \pm 3.3 \mathrm{~kg}$ (obese), $p=0.008$ ).

The Ossabaw minipig is the only breed in this study to show obesity-associated elevated serum levels of ORM (Fig. 1). Previous studies (Lee et al., 2009) have shown a high number of significant differences in blood parameters of obese Ossabaw pigs compared to lean pigs with significantly elevated levels of total cholesterol $(p=0.03)$ and triglycerides $(p=0.02)$ (and insulin, though not significantly, $p=0.10$ ). According to Christensen et al. (2012) the only obesity feature affected in domestic pig is total cholesterol $(p=0.01)$ and in the Göttingen minipigs the only obesity feature affected by obesity was fasting insulin (Moesgaard et al., in preparation). 
Table 1

Primers used for qPCR.

\begin{tabular}{|c|c|c|c|c|c|c|}
\hline Gene symbol & Gene name & Primer sequence & $\begin{array}{l}\text { Amplicon } \\
\text { length }\end{array}$ & $\mathrm{MgCl}_{2}$ & $\begin{array}{l}\text { Run } \\
\text { efficiency }\end{array}$ & $R^{2}$ \\
\hline ORM1 & Orosomucoid 1 & $\begin{array}{l}\text { F: AGTCCTGAGCCTCCTTCCTC } \\
\text { R: GCCGAGCCGATATAATACCA }\end{array}$ & 123 & $3 \mathrm{mM}$ & 1.10 & 0.988 \\
\hline GAPDH & $\begin{array}{l}\text { Glyceraldehyde-3- } \\
\text { phosphate } \\
\text { dehydrogenase }\end{array}$ & $\begin{array}{l}\text { F: ACCCAGAAGACTGTGGATGG } \\
\text { R: AAGCAGGGATGATGTTCTGG }\end{array}$ & 79 & $1.5 \mathrm{mM}$ & 1.08 & 0.992 \\
\hline RPL13A & Ribosomal protein L13a & $\begin{array}{l}\text { F: ATTGTGGCCAAGCAGGTACT } \\
\text { R: AATTGCCAGAAATGTTGATGC }\end{array}$ & 76 & $3 \mathrm{mM}$ & 0.97 & 0.997 \\
\hline
\end{tabular}

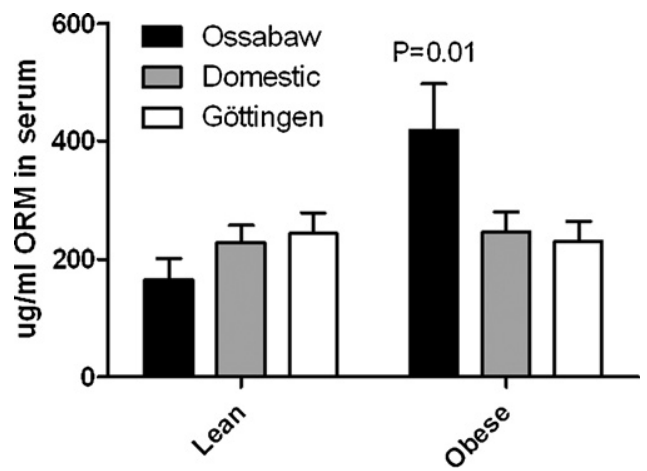

Fig. 1. Serum protein concentrations of ORM. Measured with ELISA. $n=6$ for the lean Ossabaw pigs, $n=4$ for the obese. $n=7$ for lean and obese Göttingen minipigs, and $n=9$ for the lean domestic pigs, $n=10$ for the obese.

Fig. 2 shows the expression of ORM1 in the three pig breeds. Due to gene expression below detection level in some of the Ossabaw minipig samples, the number of samples from these groups became too small for the samples to be evaluated statistically (obese VAT $n=2$, lean VAT $n=2$, obese abdominal SAT $n=2$, lean abdominal SAT $n=1$ ). Domestic and Göttingen pig groups both showed a tendency towards a decreased relative expression of ORM1 in VAT of obese compared to lean pigs ( $p=0.16$ and $p=0.12$, respectively) while in the two measurable Ossabaw VAT obese-lean sample pairs ORM1 expression was increased in the obese samples.
No changes in serum ORM concentration was observed in obese domestic pigs and obese Göttingen minipigs, however, obese Ossabaw minipigs showed a significant increase in the serum concentration of ORM compared to lean (Fig. 1). The ORM concentration in the lean group corresponded well with the baseline ORM concentration in non-obese, healthy Ossabaw pigs (unpublished).

No ORM1 mRNA response correlating with the ORM serum response was found in this study, looking at ORM1 responses in liver, abdominal SAT/RPAT, VAT and neck SAT, suggesting other sources of serum ORM. As previous studies have shown, other tissues and cells show ORM expression (Fournier et al., 2000), although not to the same level as the liver and adipose tissues (Lee et al., 2010). This is very different from the synthesis of ORM in a normal acute phase response during infection, where hepatic secretion is the main contributor to ORM in serum with no activity in the adipose tissues in several species (Fournier et al., 2000). Furthermore, it is remarkable that the response of ORM to obesity in pigs is similar to human response, with raised serum concentrations in obesity, as a previous study suggests that ORM is a negative APP in pigs during acute infection (Skovgaard et al., 2009). This fact only adds to the usability of the pig as a model for human obesity.

The Göttingen minipigs are older (41-47 months of age) than the Ossabaw minipigs (14-16 months of age) and the domestic pigs (8-9 months of age), and it is very possible that the innate immune features involved in systemic
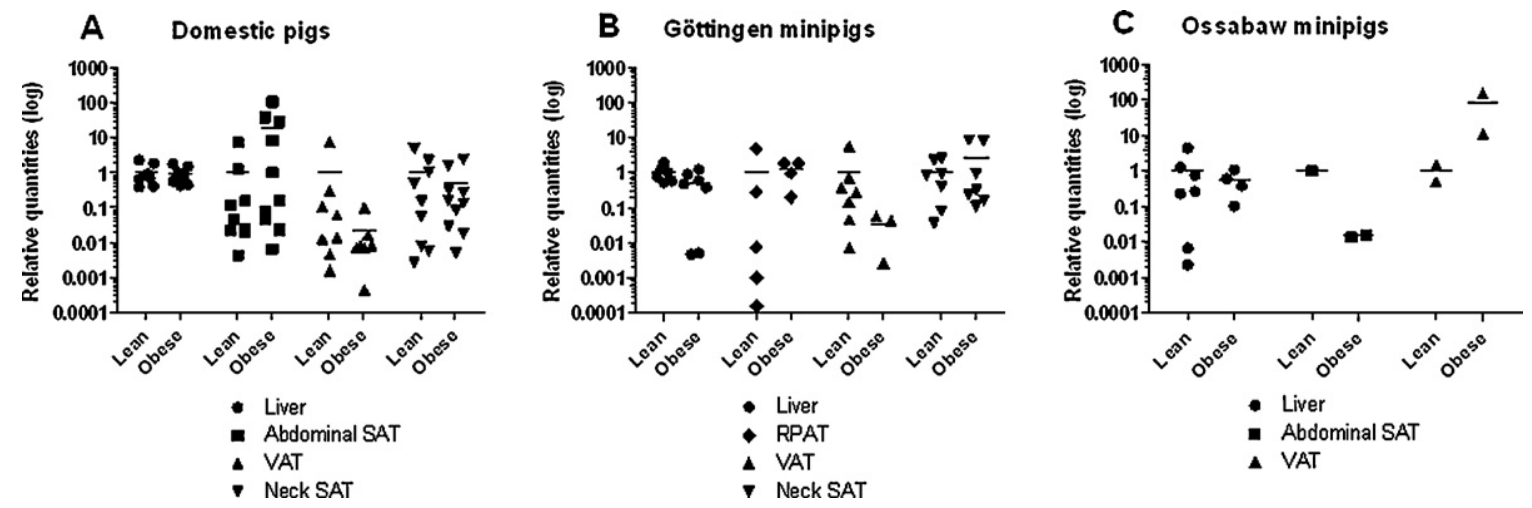

Fig. 2. Expression of ORM1 in domestic pig, Göttingen and Ossabaw minipigs in liver, abdominal SAT/RPAT, VAT and neck SAT as measured with qPCR. Relative to lean expression (set to 1 ). (A) Domestic pigs: Lean group $-n=8$ (liver and VAT), $n=9$ (abdominal and neck SAT). Obese group - $n=9$ (liver), $n=10$ (abdominal and neck SAT) and $n=7$ (VAT). (B) Göttingen minipigs: Lean group $-n=6$ (liver), $n=5$ (RPAT) and $n=7$ (VAT and neck SAT). Obese group: $n=7$ (liver and neck SAT), $n=4$ (RPAT) and $n=3$ (VAT). (C) Ossabaw minipigs: Lean group $-n=7$ (liver), $n=1$ (abdominal SAT) and $n=2$ (VAT). Obese group: $n=4$ (liver), $n=2$ (abdominal and neck SAT). 
inflammation differ with age in pigs, as in humans (Gomez et al., 2005), although no difference in gene expression was found between breeds. Another difference is that the diet of the Göttingen minipigs, in contrast to that of the other two breeds, did not contain high proportions of fat and/or sugar, which has previously been shown to result in adiposity and signs of metabolic syndrome (Dyson et al., 2006; Johansen et al., 2001; Lee et al., 2009). However, the Göttingen minipigs had been obese for a longer period of time than the other two breeds, which is closer to the situation in human obesity. In the domestic pigs, previous studies have shown that atherogenesis can be induced in domestic (Yorkshire) pigs following 4-12 weeks of feeding with excess fat and cholesterol (Gerrity et al., 1979, 2001). However, even though the domestic pigs in this study were fed a diet with excessive fat and sugar for more than 12 weeks (up to 6 months) the measured plasma indicators did not indicate atherogenesis in the obese pigs, except for the elevated total cholesterol levels (Christensen et al., 2012).

To our knowledge, no studies have compared expression of ORM in adipose tissue between obese and lean humans, therefore it was not possible to determine whether the unchanged adipose expression of ORM in obese compared to lean pigs is in agreement with human adipose tissue expression.

In summary, this investigation compares the similarities of three types of obese pig models (domestic, Göttingen and Ossabaw) and humans in terms of expression levels and serum levels of ORM. Our results, although obtained with a limited number of pigs provide evidence that only the Ossabaw minipig responds similarly to obesity as humans, with a higher serum ORM concentration in the obese pigs. This reinforces Ossabaw minipigs as a promising model for human obesity. As is the case in humans, no relationship between circulating ORM levels and its expression in either liver or adipose tissues was found in the three breeds. Furthermore, no differential expression of ORM1 in the adipose tissues were found, as in obese humans (Alfadda et al., 2012). No studies have been made into the differential mRNA expression of ORM in lean and obese humans, however, studies in mice have shown an up-regulation in adipose tissues in obese compared to lean mice (Lee et al., 2010), and it would therefore be interesting to see if this is the case as well in humans.

\section{Conflict of interest statement}

The authors declare that no conflicting financial interests exist.

\section{Acknowledgements}

Karin Tarp Wendt and Kerstin Skovgaard are acknowledged for their exceptional help with qPCR. Mette Skou Hedemann, Winnie Østergaard, Jens Askov Jensen and James P. Byrd are acknowledged for help with tissue sampling. The study of the domestic pigs was funded by a grant from the Danish Strategic Research Council (FøSU 2101-06-0034), the lean Göttingen minipigs were funded by the SHARE Foundation and Danielsen's Foundation, and the Ossabaw minipigs study was funded by United
States National Institutes of Health grants RR013223 and HL062552, Purina TestDiet Inc, and the Purdue-Indiana University Comparative Medicine Program. The study sponsors have no involvement in the publication of this article.

\section{References}

Alfadda, A., Fatma, S., Chishti, M., Al-Naami, M., Elawad, R., Mendoza, C., Jo, H., Lee, Y., 2012. Orosomucoid serum concentrations and fat depot-specific mRNA and protein expression in humans. Mol. Cells 33, 35-41.

Bastard, J.-P., Maachi, M., Lagathu, C., Kim, M.J., Caron, M., Vidal, H., Capeau, J., Feve, B., 2006. Recent advances in the relationship between obesity, inflammation, and insulin resistance. Eur. Cytokine Netw. 17, 4-12.

Bell, L.N., Lee, L., Saxena, R., Bemis, K.G., Wang, M., Theodorakis, J.L., Vuppalanchi, R., Alloosh, M., Sturek, M., Chalasani, N., 2010. Serum proteomic analysis of diet-induced steatohepatitis and metabolic syndrome in the Ossabaw miniature swine. Am. J. Physiol. Gastrointest. Liver Physiol. 298, G746-G754.

Bellinger, D.A., Merricks, E., Nichols, T., 2006. Swine models of Type II diabetes mellitus: insulin resistance, glucose tolerance, and cardiovascular complications. ILAR J. 47, 243-258.

Christensen, K.L., Hedemann, M.S., Jørgensen, H., Stagsted, J., Knudsen, K.E., 2012. Liquid chromatography-mass spectrometry based metabolomics study of cloned versus normal pigs fed either restricted or ad libitum high-energy diets. J. Proteome Res. 11 (7), 3573-3580.

Dyson, M., Boullion, R., Alloosh, M., Mokelke, E., Sturek, M., 2006. Components of metabolic syndrome and coronary artery disease in female Ossabaw swine fed excess artherogenic diet. Comp. Med. 56, 35-45.

Ebeling, P., Teppo, A.-M., Koistinen, H.A., Viikari, J., Rönnemaa, T., Nissén, M., Bergkulla, S., Salmela, P., Salveto, J., Koivisto, V.A., 1999. Troglitazone reduces hyperglycaemia and selectively acute-phase serum proteins in patients with Type II diabetes. Diabetologia 42, 1433-1438.

Fain, J.N., 2010. Release of inflammatory mediators by human adipose tissue is enhanced in obesity and primarily by the nonfat cells: a review. Mediators Inflamm. 2010.

Fantuzzi, G., 2005. Adipose tissue, adipokines, and inflammation. J. Allergy Clin. Immunol. 115, 911-919.

Federico, A., D’Aiuto, E., Borriello, F., Barra, G., Gravina, A.G., Romano, M., De Palma, R., 2010. Fat: a matter of disturbance for the immune system. World J. Gastroenterol. 16, 4762-4772.

Fournier, T., Medjoubi, N., Porquet, D., 2000. Alpha-1-acid glycoprotein. Biochim. Biophys. Acta 1482, 157-171.

Gerrity, R.G., Naito, H.K., Richardson, M., Schwartz, C.J., 1979. Dietary induced atherogenesis in swine. Am. J. Pathol. 95, 775-793.

Gerrity, R.G., Natarajan, R., Nadler, J.L., Kimsey, T., 2001. Diabetes-induced accelerated atherosclerosis in swine. Diabetes 50, 1654-1665.

Gil, A., Aguilera, C.M., Gil-Campos, M., Cañete, R., 2007. Altered signalling and gene expression associated with the immune system and the inflammatory response in obesity. Br. J. Nutr. 98, S121-S126.

Gomez, C.R., Boehmer, E.D., Kovacs, E.J., 2005. The aging innate immune system. Curr. Opin. Immunol. 17, 457-462.

Grubbs, F.E., 1969. Procedures for detecting outlying observations in samples. Technometrics 11,1-21.

Hochepied, T., Berger, F.G., Baumann, H., Libert, C., 2003. $\alpha 1$-Acid glycoprotein: an acute phase protein with inflammatory and immunomodulating properties. Cytokine Growth Factor Rev. 14, 25-34.

Johansen, T., Hansen, H.S., Richelsen, B., Malmlöf, K., 2001. The obese Göttingen minipig as a model of the metabolic syndrome: dietary effects on obesity, insulin sensitivity, and growth hormone profile. Comp. Med. 51, 150-215.

Lee, L., Alloosh, M., Saxena, R., Van Alstine, W., Watkins, B.A., Klaunig, J.E., Sturek, M., Chalasani, N., 2009. Nutritional model of steatohepatitis and metabolic syndrome in the Ossabaw miniature swine. Hepatology 50, 56-67.

Lee, Y.S., Choi, J.W., Hwang, I., Lee, J.W., Lee, J.H., Kim, A.Y., Huh, J.Y., Koh, Y.J., Koh, G.Y., Son, H.J., Masuzaki, H., Hotta, K., Alfadda, A.A., Kim, J.B., 2010. Adipocytokine orosomucoid integrates inflammatory and metabolic signals to preserve energy homeostasis by resolving immoderate inflammation. J. Biol. Chem. 285, 2217.4-2218.5.

Litten-Brown, J.C., Corson, A.M., Clarke, L., 2010. Porcine models for the metabolic syndrome, digestive and bone disorders: a general overview. Animal 4 (6), 899-920.

Ridker, P.M., Buring, J.E., Shih, J., Matias, M., Hennekens, C.H., 1998. Prospective study of C-reactive protein and the risk of future 
cardiovascular events among apparently healthy women. Circulation 98, 731-733.

Ridker, P.M., Hennekens, C.H., Buring,J.E., Rifai, N., 2000. C-reactive protein and other markers of inflammation in the prediction of cardiovascular disease in women. N. Engl. J. Med. 342, 836-843.

Rødgaard, T., Skovgaard, K., Stagsted, J., Heegaard, P.M.H., 2012. Expression of innate immune response genes in liver and three types of adipose tissue in cloned pigs. Cell Reprogram. 14 (5), 407-417.

Skovgaard, K., Mortensen, S., Boye, M., Poulsen, K., Campbell, F., Eckersall, P., Heegaard, P., 2009. Rapid and widely disseminated acute phase protein response after experimental bacterial infection of pigs. Vet. Res. 40, 23.
Stone, R.T., Maurer, R.A., 1987. Cloning and developmental regulation of alpha 1 acid glycoprotein in swine. Dev. Genet. 8, 295-304.

Vandesompele, J., De Preter, K., Pattyn, F., Poppe, B., Van Roy, N., De Paepe, A., Speleman, F., 2002. Accurate normalization of real-time quantitative RT-PCR data by geometric averaging of multiple internal control genes. Genome Biol. 3, research0034.1-0034.11.

Williams, J.P., Weiser, M.R., Pechet, T.T.V., Kobzik, L., Moore, F.D. Hechtman, H.B., 1997. $\alpha$-Acid glycoprotein reduces local and remote injuries after intestinal ischemia in the rat. Am. J. Physiol. 273, G1031-G1035. 